\title{
Estimated impacts of soil degradation on the African water balance and climate
}

\author{
Johannes J . Feddema* \\ Department of G eography, University of Kansas, Lawrence, Kansas 66045, USA
}

\begin{abstract}
This study uses a well-established water balance methodology, the Thornthwaite-M ather approach, to evaluate the effects of soil water holding capacity assumptions on estimates of African evapotranspiration rates, moisture deficit, and moisture surplus conditions. Under constant climate conditions, the model tests the impact of using a constant $150 \mathrm{~mm}$ soil water holding capacity compared to using a newly derived soil water holding capacity data set (the Dunne-Willmott data set). The study also uses a worldwide survey of soil degradation between 1950 and 1980 (GLASOD: Global Assessment of Soil Degradation) to evaluate the impacts of human-induced soil degradation on local water balances. The GLASOD data are used to alter local soil water holding capacities based on the DunneWillmott data to simulate human soil degradation patterns in Africa. Results indicate that the use of simplified soil water holding capacities can lead to significant errors in estimated evapotranspiration rates and water surplus and deficit conditions in Africa. Regions most affected are those with seasonal wet and dry climates, which are also those locations with the greatest climate variability. Because these are often the climates most studied to detect and model environmental change, it is important that accurate soil moisture estimates be used to simulate climate conditions in these regions. Results also indicate that soil degradation occurring over a $30 \mathrm{yr}$ period (1950 to 1980) has had a significant impact on local water resources. The greatest impacts of these changes are in some of the more productive agricultural areas in the wetter sub-humid climates. Changes include increased runoff during wet seasons and an extended drought period during the dry seasons. Given that these agricultural systems have less flexibility to respond to long-term desiccation as compared to pastoral systems, this could lead to significant changes in local growing seasons and perhaps overall productivity in the future.
\end{abstract}

KEY WORDS: Climate change $\cdot$ Soil degradation · Africa $\cdot$ Water balance

\section{INTRODUCTION}

Human actions on the environment have been linked to a number of potential climate impacts. Some examples of these include the greenhouse effect, urban warming, the effects of large-scale deforestation on water and energy balances, and impacts of land-use change on surface albedos and related climatic feedbacks (e.g. Charney 1975, Mabbutt 1989, Nicholson 1989, Houghton et al. 1990, 1992). This study will demonstrate the need for accurate estimates of soil water holding capacities to model water balances and human impacts on local climate conditions effectively. Africa is used as a test case to show that these assump-

\footnotetext{
*E-mail: feddema@falcon.cc.ukans.edu
}

tions are particularly important in seasonal wet and dry climates. The study will also present a methodology and a preliminary analysis to evaluate the largescale impacts of human soil degradation on the African water balance. Specifically, it will simulate the impact of land degradation on soil water holding capacities, and the subsequent impacts on evapotranspiration rates, moisture surplus and moisture deficit conditions. Changing soil water holding properties will have far reaching consequences not only for African water resource issues, but also for local and regional climates.

Soil degradation is a long standing environmental issue linked to a wide variety of human activities, with known impacts reaching back millennia, e.g. in M esopotamia, North Africa during Roman times, the Dust Bowl in North America earlier this century, and cur- 
rently China and Africa in particular (e.g. Thomas \& Middleton 1994). Often the effects of soil degradation become most evident during periods of adverse (dry) climate conditions as is evident in the examples cited. Soil degradation is not only linked to adverse climate changes; it has been shown to be an ongoing concern worldwide (Middleton \& Thomas 1992, Syers et al. 1996). As population pressure increases and societies change from one agrarian management practice to another, large-scale impacts on soil conditions tend to follow (Mabbutt 1989, Nicholson 1989, Hulme 1994, Syers et al. 1996, Warren et al. 1996). M ost frequently these impacts result in vegetation change, top soil loss and the erosion of soil from arable lands, sometimes rendering these lands unsuitable for further agricultural use (Middleton \& Thomas 1992, Hulme \& Kelly 1993). The results of land degradation include changes in local vegetation structure, soil water holding capacities, soil permeability and surface albedo (Bryant et al. 1990, Schlesinger et al. 1990, Thomas \& Middleton 1994).

A recent worldwide survey of soil degradation (Oldeman 1988, Oldeman et al. 1990, Middleton \& Thomas 1992) will be used in this study to assess the impacts of humans on soil water holding capacities on the African continent. Using a well-established water balance methodology (Thornthwaite 1948, Thornthwaite \& M ather 1955, M ather 1978, Feddema \& M ather 1992, Feddema 1998) this study will combine the human soil degradation data with a new soil water holding capacity data set (Dunne \& Willmott 1996) to provide an estimate of the impacts of human soil degradation on African water resources. To put the soil degradation results in perspective, the study will first demonstrate the sensitivity of water balance models to soil water holding capacities. A frica will be used as a test case to compare the use of a constant $150 \mathrm{~mm}$ soil water holding capacity versus using derived soil water holding capacities developed by Dunne \& Willmott (1996). Results will demonstrate that the seasonal wet and dry climate regions of the Earth are particularly sensitive to soil water holding capacity assumptions in hydrologic models.

\section{BACKGROUND}

Human alteration of the Earth's surface is an ongoing problem frequently discussed in the literature (e.g. see Thomas \& M iddleton 1994, Williams \& Balling 1996). Most commonly this issue is discussed in terms of 'desertification', particularly when related to dryland ecosystems. Most early studies focused on the influence of climate in the desertification process (e.g. Kemp 1991). However, particularly since the work by
Charney (1975), there has been a significant body of literature on the effects of surface changes on climate from a wide variety of perspectives (e.g. Dregne 1983, El-Baz \& Hassan 1986, Mabbutt 1989, Nicholson 1989, Bryant et al. 1990, Hulme 1994, Warren et al. 1996, Williams \& Balling 1996). Williams \& Balling (1996) provide an excellent background on the known effects of desertification on climate.

Most of the analyses relating human-caused land degradation to climate change focus on changes in the energy balance of an environment, including the effects of albedo changes in general ( ackson \& Idso 1975) and more specifically albedo changes associated with salinization (Williams \& Balling 1996), the effects of overgrazing (Bryant et al. 1990), the impacts of vegetation removal due to various causes and the impacts of increased dust concentrations in the atmosphere (for example, see Charney 1975, Mabbutt 1989, Nicholson 1989, Bryant et al. 1990, Williams \& Balling 1996). In the last few decades, many models have tried to simulate the impacts of land-use change on local climates, showing that surface changes can have significant impacts on local climate conditions (Charney 1975, Lare \& Nicholson 1990, Nicholson \& Lare 1990, Franchito \& Rao 1992, Zheng \& Eltahir 1997). These models support the idea that local albedo changes will have impacts on local energy balances and can affect mesoscale circulation events.

M ore recent models, based on GCM s (general circulation models), have attempted to simulate the effects of desertification further by forcing surface parameters such as albedo and vegetation characteristics (e.g. Sud et al. 1993, Xue \& Shukla 1993). In addition, a significant amount of attention has been paid to the effects of soil moisture conditions (wet vs dry) on climates (e.g. Walker \& Rowntree 1977, Shukla \& Mintz 1982, Manabe \& Wetherald 1987, Xue \& Shukla 1993). Results from these models indicate that soil moisture conditions can have a large influence on local circulation and precipitation patterns. More recently, in the context of Nile water resources, Conway et al. (1996) demonstrate the potential impacts of a number of global and local human impacts using a water balance model. But like most models they do not specifically address the impacts of realistic soil degradation estimates on water resources. In most of these studies, soil moisture holding capacities are held constant, or are changed crudely with vegetation type. Little account is taken of changes in soil conditions or the effects of soil degradation on climate, and none of these studies attempt to change soil conditions realistically based on empirical evidence of soil degradation.

In general, it is recognized that soil degradation will result in decreased soil water holding capacities, with a consequent increase in runoff and decrease in actual 
evapotranspiration (e.g. M abbutt 1989, Nicholson 1989, Bryant et al. 1990, Williams \& Balling 1996). In energy balance terms, the proportion of surface energy lost through sensible heat loss will increase, and the latent heat flux will decrease, resulting in increased surface temperatures. Bryant et al. (1990) demonstrated the difference in energy balance terms in degraded and control environments along the U.S. and Mexico border. They showed that the differences in the energy balance are most pronounced about $3 \mathrm{~d}$ after rain events, when the control plots retained soil moisture for a longer period, keeping the latent heat flux high and reducing surface temperatures in those environments (Bryant et al. 1990). In addition, Balling (1991) has shown that there is a statistically significant relationship between regions experiencing desertification and increased local temperatures, and concludes that this is primarily due to changes in the Bowen Ratio (see also Williams \& Balling 1996). M abbutt (1989) also supports the idea that water availability is a primary cause of local climate modification associated with desertification. Unlike these previous studies, this paper uses new databases to introduce a method for assessing the impacts of soil degradation on local climates and water resources.

\section{METHODS}

Several existing data sets and an established water balance model will be modified to: (1) test the validity of assuming a constant soil water holding capacity; and (2) simulate the effects of soil degradation on the African water balance. The model, climate input data, soil water holding capacity data, and the simulation of soil degradation will be discussed in turn, and then each experiment will be described.

\subsection{The water balance model}

To estimate the impacts of human soil degradation on African water resources, this study will use a distributed water balance analysis. The regional water balance model is based on the Thornthwaite-Mather approach (Thornthwaite 1948, Thornthwaite \& Mather 1955). This method was selected for this study for several reasons. First, because of the scarcity of climatic and land-use data for Africa, the methods for estimating potential evapotranspiration are required to use minimal climate inputs. Second, this method has been well tested, and while there are some drawbacks to the potential evapotranspiration $\left(E_{p}\right)$ scheme (e.g. Hulme et al. 1994, 1996), it has been shown to be at least as effective as alternative, more complicated and data-intensive techniques in recent water balance studies (Mintz \& Serafini 1992, Mintz \& Walker 1993, Vörösmarty et al. 1993, Federer et al. 1996). One source of the discrepancy between the Thornthwaite estimates of $E_{p}$ and other methods is related to the definition of $E_{p}$ used. The Thornthwaite method was developed using watershed measures of precipitation and runoff and assumes that $E_{p}$ is measured over a well-watered vegetated surface. Most studies comparing the $E_{p}$ techniques use lysimeter measurements to validate models (Wilm et al. 1944, Mather \& Ambroziak 1986). In dry locations lysimeters measurements typically overestimate $E_{p}$ rates due to very dry atmospheric and environmental conditions surrounding the instrument, while true values of $E_{p}$ would typically be measured under higher humidity conditions over a vegetated surface. Third, because of frequent use in previous studies of water resources, this method allows for comparison of water resource changes with prior work, in particular a similar scheme used in Feddema \& Mather (1992) and Feddema (1998) to evaluate water resources in the U.S. and Africa under global warming conditions.

The water balance model is the same as that used by Willmott et al. (1985). Although the model considers snow accumulation and snowmelt, this will not be discussed here because snow is a negligible component of African precipitation. The model is based on the following governing equations, with the overall water balance represented by (Willmott et al. 1985):

$$
\frac{\partial \mathrm{w}}{\partial \mathrm{t}}=\mathrm{P}_{\mathrm{r}}-\mathrm{E}_{\mathrm{a}}-\mathrm{S}
$$

where $\mathrm{w}$ represents soil water content $\left(0 \geq \mathrm{w} \geq \mathrm{w}^{*}\right.$, where $w^{*}$ represents soil water holding capacity), $\mathrm{P}_{r}$ is the rainfall rate, $E_{a}$ the actual evapotranspiration rate, and $\mathrm{S}$ the water surplus of a location. $\mathrm{E}_{\mathrm{a}}$ is calculated as follows:

$$
E_{a}= \begin{cases}P_{r}+\beta\left(w, W^{*}\right)\left(E_{p}-P_{r}\right), & P_{r}<E_{p} \\ E_{p}, & P_{r} \geq E_{p}\end{cases}
$$

where $E_{p}$ is potential evapotranspiration and $\beta\left(w, w^{*}\right)$ is a soil moisture retention function dependent on the ratio of $\mathrm{w}$ and $\mathrm{w}^{*}$. Potential evapotranspiration is calculated by the Thornthwaite method as follows:

$$
E_{p}^{\prime}= \begin{cases}0, & T<0^{\circ} \mathrm{C} \\ 16\left(\frac{10 T}{I}\right)^{a}, & 0 \leq T<26.5^{\circ} \mathrm{C} \\ -415.85+32.24 T-0.43 T^{2}, & T \geq 26.5^{\circ} \mathrm{C}\end{cases}
$$

where $E_{p}$ is monthly unadjusted potential evapotranspiration, $T$ is mean monthly surface air temperature $\left({ }^{\circ} \mathrm{C}\right)$, and $\mathrm{I}$, the annual heat index, is: 


$$
I=\sum_{i=1}^{12}\left(\frac{T_{i}}{5.0}\right)^{1.514}
$$

and a is:

$$
\begin{aligned}
a= & 6.75 \times\left. 10^{-7}\right|^{3}-7.71 \times\left. 10^{-5}\right|^{2} \\
& +1.79 \times 10^{-2} \mid+0.49
\end{aligned}
$$

Potential evapotranspiration is adjusted for variable day $(h)$ and month $(\theta)$ lengths:

$$
E_{p}=E_{p}^{\prime} \frac{\theta}{30} \frac{h}{12}
$$

The soil moisture retention function $\beta\left(w, w^{*}\right)$ is determined as follows:

$$
\beta\left(w, w^{*}\right)= \begin{cases}1, & w>0.7 w^{*} \\ \frac{1}{0.7} \frac{w}{w^{*}}, & w \leq 0.7 w^{*}\end{cases}
$$

This means that soil moisture extraction simulates a 2 -layer model where the top layer (30\% of the total water holding capacity) will release water freely for evapotranspiration purposes, and the lower layer (containing $70 \%$ of total soil water holding capacity) will make water available at a linearly decreasing rate until all the water is used up (soil moisture retention curve $\mathrm{G}$ in Mather 1978).

M oisture surplus conditions are calculated as foll ows:

$$
\mathrm{S}= \begin{cases}\mathrm{P}_{\mathrm{r}}-\left[\mathrm{E}_{\mathrm{a}}+\left(\mathrm{w}^{*}-\mathrm{w}\right)\right], & \mathrm{P}_{\mathrm{r}}>\mathrm{E}_{\mathrm{a}}+\left(\mathrm{w}^{*}-\mathrm{w}\right) \\ 0, & \mathrm{P}_{\mathrm{r}} \leq \mathrm{E}_{\mathrm{a}}+\left(\mathrm{w}^{*}-\mathrm{w}\right)\end{cases}
$$

Both $E_{a}$ and $S$ are calculated on a daily time step from the beginning to the end of a month assuming equal values of $E_{p}$ for each day of the month. This gives estimates of $w$ at the beginning and end of each month, and thus a monthly value of $\partial \mathrm{w} / \partial \mathrm{t}$ (see Willmott 1977 and Willmott et al. 1985 for details). For this climatic-average application, the water budget is iteratively balanced until $w$ for $J$ anuary 1 is the same on consecutive passes. Finally the moisture deficit $D$ is calculated as:

$$
D=E_{p}-E_{a}
$$

Model input requirements include monthly average temperature and precipitation estimates, a soil water holding capacity value $\left(w^{*}\right)$ and the latitude of the location. The model will be run under several different scenarios to represent control and degraded soil conditions which are based on changed soil water holding capacities. Results will present changes in mean annual values of water surplus (S), water deficit (D) and actual evapotranspiration $\left(E_{a}\right)$.

\subsection{Climate data}

The water balance model requires several climate inputs. Because this study does not focus on climate change as a forcing factor, the high density monthly temperature and precipitation climatologies developed by Legates \& Willmott $(1990 a$, b) interpolated to the same $0.5^{\circ}$ lattice as the soil data are used. While these data have been criticized for their use of station records of variable time periods (e.g. Hulme et al. 1992) their high station densities allow for a much higher spatial resolution compared to several other available data sources, and thus provide an ideal base condition for this experiment. Fig. la \& c show the gridded temperature (Legates \& Willmott 1990b) and precipitation values for Africa (Legates \& Willmott 1990a). Based on the Legates \& Willmott (1990b) temperature data, estimates of potential evapotranspiration were produced using the Thornthwaite model (Wilm et al. 1944; Eqs. 3 to 6) (Fig. 1b). Area-weighted continent-averaged statistics are presented with each of the figures. These climate inputs remained constant for all subsequent model runs discussed here.

Over the whole continent, precipitation only averages about one-half of the total climatic water demand based on the $E_{p}$ statistics (see Fig. 1b). A frican $E_{p}$ climatology (Fig. lb) varies from about $600 \mathrm{~mm} \mathrm{yr}^{-1}$ to about $1900 \mathrm{~mm} \mathrm{yr}^{-1}$ in a pattern similar to that of the temperature climatology (Fig. 1a). Values below $800 \mathrm{~mm} \mathrm{yr}^{-1}$ are found in the highland areas of east Africa, and the Atlas and Drakensberg mountain areas. The highest values are found in the Sahara and Somali deserts. Because of the nonlinear relationship between temperature and $E_{p}$, the overall pattern of $E_{p}$ is similar to that of temperature, but the gradients between the high and low regions are shifted compared to the gradients observed on the temperature map. In contrast, precipitation shows maxima over the west equatorial region and along the Gulf of Guinea coast, with minima in the Sahara, Somali, and Kalahari desert regions.

\subsection{Soil water holding capacity}

Estimation of soil water holding capacity is a difficult proposition, especially for large areas. Soil characteristics and profiles are highly variable from place to place, and depend on a variety of different factors including substrate properties, organic content of the soil, vegetation types, rooting depths, etc. (e.g. Dunne \& Leopold 1978, Mather 1978). For many water resource and climate studies, water holding capacities are set to a constant value, most often $150 \mathrm{~mm}$ (e.g. Willmott et al. 1985, Feddema \& Mather 1992) or $100 \mathrm{~mm}$ (e.g. Slatyer 1960, cited in Williams \& Balling 1996); in other cases it is allowed to vary crudely with vegetation type (e.g. Xue \& Shukla 1993). For this study 2 estimates of soil water holding capacity will be 


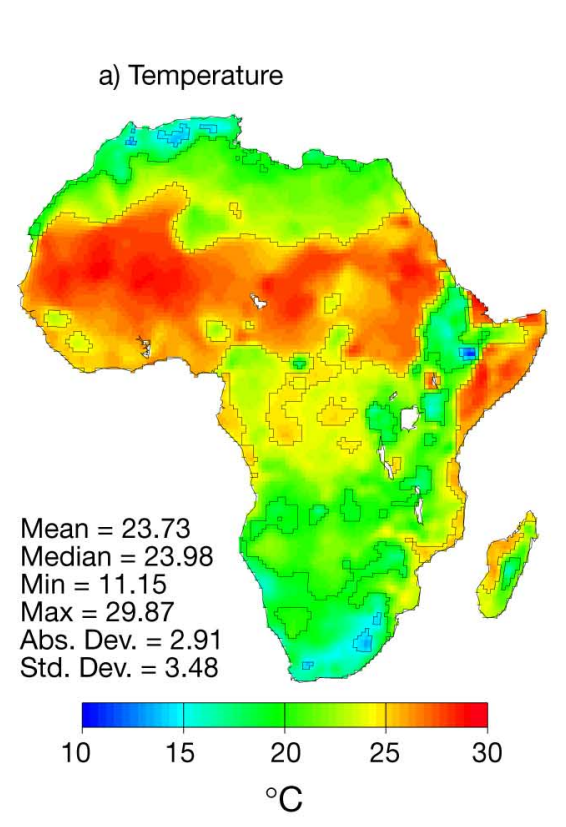

\section{Climate Input}

b) Potential Evapotranspiration

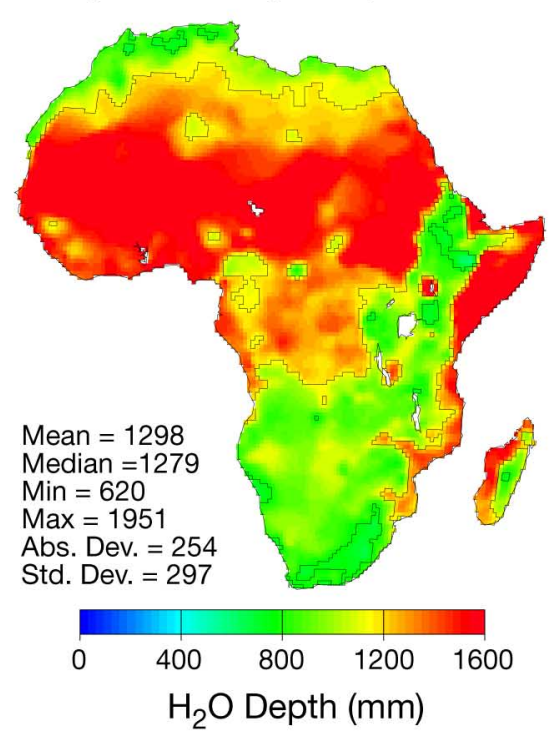

c) Precipitation

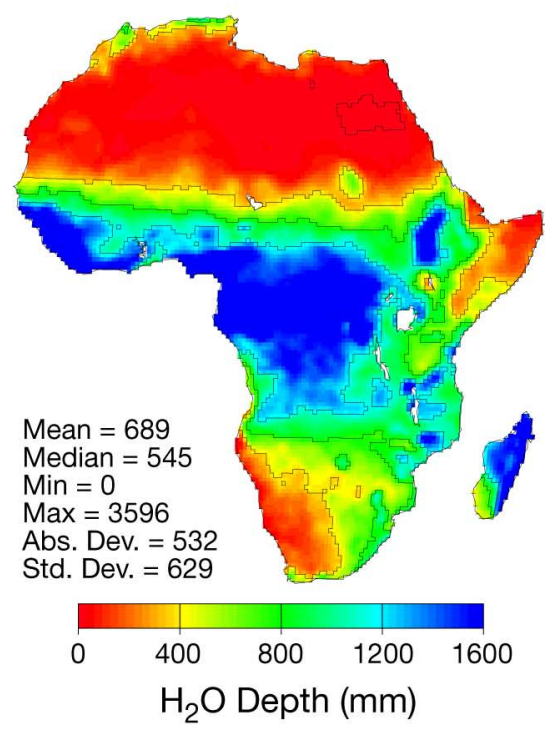

Fig. 1. Mean climate conditions used as input to the water balance model: (a) temperature estimates from Legates $\&$ Willmott (1990b); (b) potential evapotranspiration rates using the Thornthwaite method; and (c) precipitation estimates from Legates \& Willmott (1990a)

used: (1) a constant $150 \mathrm{~mm}$ value for the entire continent, and (2) the global plant-extractable soil water capacity data developed by Dunne \& Willmott (1996; $D \& W$ hereafter). The soil water holding capacity values used in this study represent only plant-extractable water and not field capacity, which includes water not available to plants or release to the atmosphere.

Although there are some crude assumptions in the D\&W-derived soil water holding capacity estimates (Dunne \& Willmott 1996), it will be used as a standard against which to measure the impacts of assuming a constant soil water holding capacity and the impacts of desertification. The D\&W data set is considered preferable over assuming a constant water holding capacity because it incorporates the spatial variability associated with major soil and vegetation characteristics in its estimation of soil water holding capacities. Results from this study are intended to show the potential gains that can be made by incorporating complex surface parameters into climate and environmental modeling efforts.

For the purposes of this study, the $D \& W$ data were modified slightly. In the original classification, areas without vegetative cover were not assigned a soil water holding capacity. In this study any unvegetated area was assigned a $5 \mathrm{~mm}$ soil water holding capacity. This value was assigned on the assumption that many of these areas are surface bedrock. However, in some cases, this assumption could be a problem, e.g. where nonvegetated areas represent such features as dune fields. However, almost all the nonvegetated locations are in the Sahara desert, and regardless of their water storage capacity, they have little or no influence on the results of this study. Fig. 2a illustrates the modified $\mathrm{D} \& W$-derived soil water holding capacities at the original $0.5^{\circ}$ lattice. The greatest soil water holding capacities are found in sandy soil regions such as eastern Ethiopia and Somalia, and portions of the northern Sahel region. High soil water holding capacities are also found in the deep soils associated with woodland savanna regions (northern and southern Republic of Congo, and portions of M adagascar), and in portions of the Mediterranean coastal areas. Lower soil water holding capacities are found in the leached tropical forest regions of the Congo Basin, in shallow rooted savanna regions and in most desert locations.

\subsection{Estimating human-induced soil degradation}

Human impacts on soil are numerous and have been extensively described in any number of studies (Mabbutt 1989, Schlesinger et al. 1990, Middleton \& Thomas 1992, Thomas \& Middleton 1994, Williams \& Balling 1996). For the purposes of this study, the International Soil Reference Centre (ISRIC) and United Nations Development Programme (UNEP) sponsored 1987 Global Assessment of Soil Degradation (GLASOD) will be used to represent human-induced soil degradation between 1950 and 1980 (Oldeman 1988, Oldeman et 
a) Soil water holding capacity

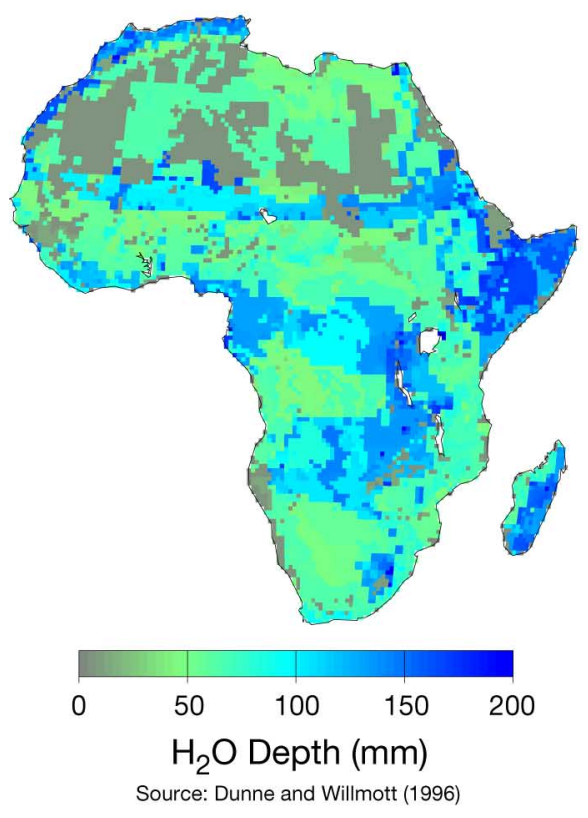

b) Desertification severity factor

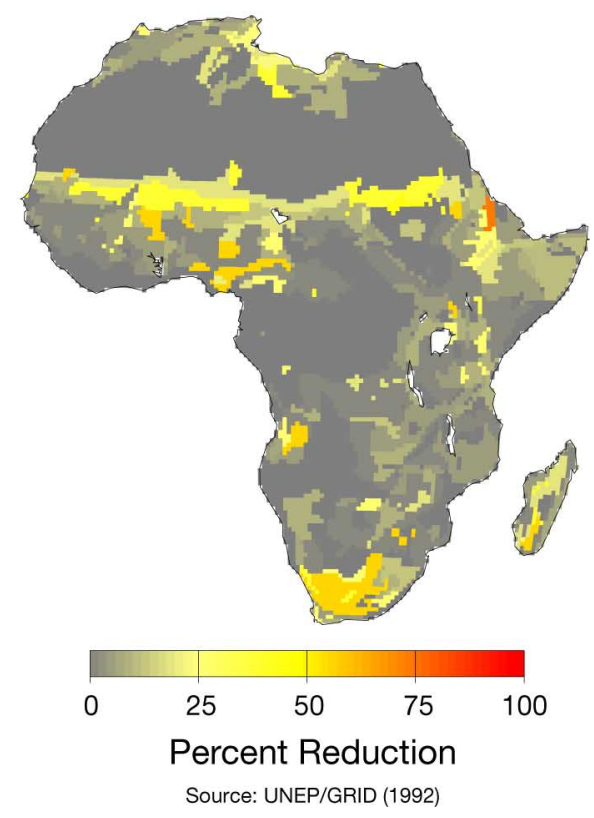

Fig. 2. African soil characteristics: (a) the soil water holding capacities modified from Dunne \& Willmott (1996); and (b) the estimates soil water holding capacity reduction factor due to soil degradation processes al. 1990, Middleton \& Thomas 1992). While there are critiques of the methodology used in this study (see Thomas \& Middleton 1994), this type of general database seems ideal for developing human-induced soil degradation scenarios to be used in climate assessment studies. GLASOD used over 250 local soil experts to evaluate the status of soil degradation in their local regions (Oldeman 1988, Oldeman et al. 1990).

GLASOD identifies a primary and secondary cause of erosion, and the degree and extent of each cause for homogeneous natural physiographic areas. The data were obtained through the UNEP GRID program (see Middleton \& Thomas 1992). The original data are available as an ARC/Info vector format file. However, for the purposes of this study, the data were converted to a $0.5^{\circ}$ lattice to make it compatible with other data sources used in the study. To estimate the impact of erosion on soil water holding capacities $(w *)$, a methodology similar to that employed by GLASOD to determine overall severity of degradation was used (Oldeman 1988, Middleton \& Thomas 1992).

Using sets of weighting functions to describe quantitatively the impact of each cause, degree and extent of erosion, an overall soil water holding capacity reduction factor (RF) was calculated for each area:

$$
R F=\sum_{i=1}^{2}\left(W F_{\text {cause }}\right)_{i}\left(W F_{\text {degree }}\right)_{i}\left(W F_{\text {extent }}\right)_{i}
$$

where $W F_{\text {cause }}$ represents the weighting factor assigned to the cause of soil degradation at the location, $W F_{\text {degree }}$ is the numerical weighting factor assigned to the observed degree of erosion due to the cause;
$\mathrm{WF}_{\text {extent }}$ is the numerical weighting factor assigned to the observed extent of erosion by the cause, and the subscript represents the primary and secondary causes of soil degradation.

GLASOD identifies 12 different soil degradation types. Only those considered to have a direct impact on soil water holding capacities were selected for this study and assigned weights representing their relative impact (Table 1). For example, top soil loss was

Table 1. Causes of soil degradation from GLASOD (Oldeman 1988). Categories and weighting factors used for this study are shown in bold type. Types that did not occur in the study area are in italic type. Types considered to have no impact are in normal type

\begin{tabular}{|lc|}
\hline Categories & Weighting factor \\
\hline Water erosion & \\
Loss of top soil & $\mathbf{1 . 0 0}$ \\
Terrain deformation & $\mathbf{0 . 7 5}$ \\
Wind erosion & \\
Loss of top soil & $\mathbf{1 . 0 0}$ \\
Terrain deformation & $\mathbf{0 . 7 5}$ \\
Overblowing & $-\mathbf{0 . 5 0}$ \\
Chemical deterioration & \\
Loss of nutrients & 0.00 \\
Salinization & 0.00 \\
Pollution & 0.00 \\
Acidification & 0.00 \\
Physical deterioration & \\
Compaction & $\mathbf{1 . 0 0}$ \\
Waterlogging & 0.00 \\
Subsidence of organic soils & 1.00 \\
\hline
\end{tabular}


assigned a weighting factor of 1.00 compared to a weighting factor of 0.75 for soil deformation (e.g. gullying), meaning that top soil loss is considered to have a greater impact on reducing a soil's water holding capacity. Similarly, overblowing adds soil to a region and increases the water holding capacity of a soil. Hence overblowing was assigned a weighting factor of -0.5 to indicate that it will increase current water holding capacities. The 0.5 weighting is assigned on the assumption that windblown sand is low in organic content, making it less effective at holding soil moisture than better developed organic-rich soils. Those categories listed in GLASOD that were considered to have little or no impact in a soil's water holding capacity were ignored in the study (weighting factor 0.00 ).

In addition to identifying the type of soil degradation for each area, the GLASOD database also contains information regarding the extent and the degree to which the degradation cause is present in the area examined. This study uses the same weighting schemes used by GLASOD (Oldeman 1988, Oldeman et al. 1990) and the World Desertification Atlas (Middleton \& Thomas 1992) to assess quantitatively the degree and extent of erosion associated with a specific cause. The weighting schemes used to assess the degree of de-
Table 2. Degrees of soil degradation provided in GLASOD (Oldeman 1988) and weighting factors used for this study

\begin{tabular}{|lc|}
\hline Categories & Weighting factor \\
\hline Unaffected & 0.00 \\
Slight & 0.25 \\
Moderate & 0.50 \\
Strong & 0.75 \\
Extreme & 1.00 \\
\hline
\end{tabular}

Table 3. Extent of soil degradation from GLASOD (OIdeman 1988) and weighting factors used for this study

\begin{tabular}{|lcc|}
\hline Categories & Area affected & Weighting factor \\
\hline Infrequent & $0-5 \%$ & 0.025 \\
Common & $5-10 \%$ & 0.075 \\
Frequent & $10-25 \%$ & 0.175 \\
Very frequent & $25-50 \%$ & 0.375 \\
Dominant & $>50 \%$ & 0.750 \\
\hline
\end{tabular}

gradation are shown in Table 2. Similarly, Table 3 illustrates the weighting factors used to represent the extent of an area affected by the given soil degradation factor. a) Type of Erosion

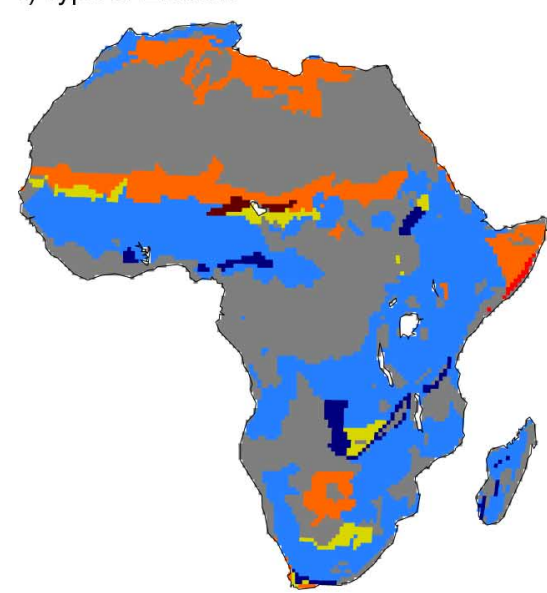

Water

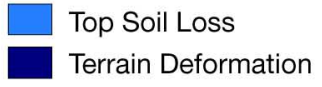

Wind

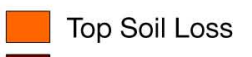

Terrain Deformation

Overblowing

Jther Soil Compaction Unaffected

\section{Primary desertification cause}
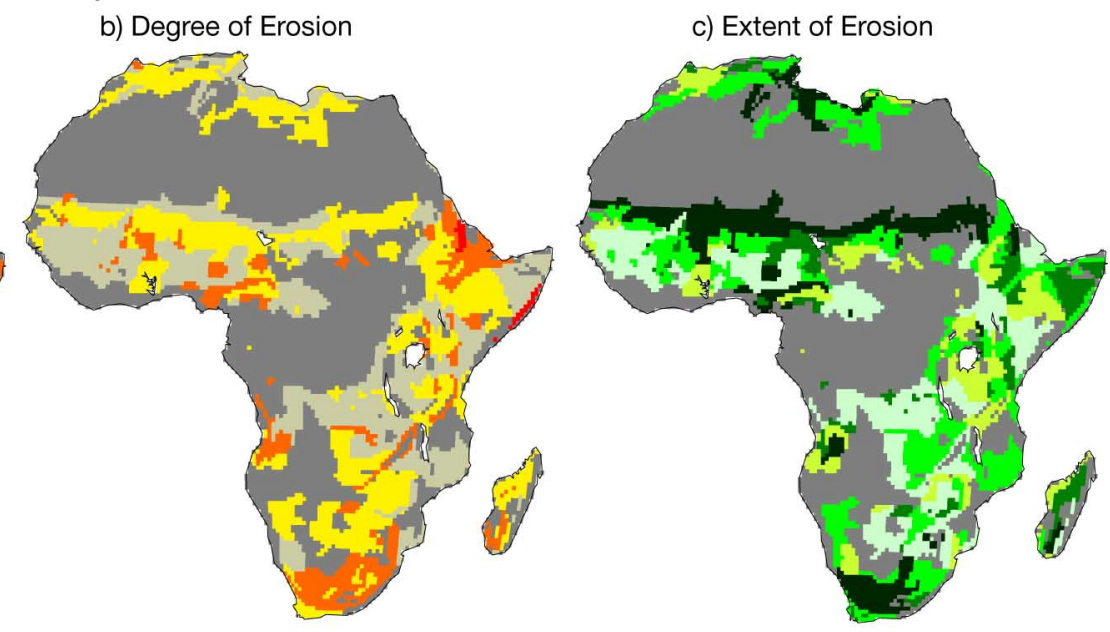

Unaffected

Slight

Moderate

Strong

Extreme

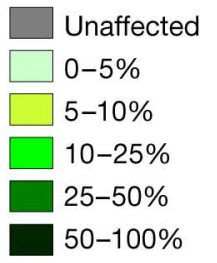

Source: UNEP/GRID (1992)

Fig. 3. Spatial distribution of (a) the primary causes of soil degradation, (b) the degree of erosion from these causes, and (c) the spatial extent of erosion from these causes on the A frican continent. Source: GLASOD (OIdeman 1988) 
For each location GLASOD identified a primary and secondary cause of soil degradation. Fig. 3a, b \& c illustrate the spatial distribution of the 6 primary soil degradation causes assessed in this study (see Table 1) and their degree and extent on the African continent. Similarly, Fig. 4 shows the cause, degree and extent of the secondary causes of soil degradation used in this study. From these figures it is clear that most soil degradation is due to the loss of top soil from water erosion. There are a number of causes for the increased loss of top soil to water erosion, mainly the removal of protective vegetation cover from (over)grazing activities and poor management practices on agricultural fields (see Middleton \& Thomas 1992 for a complete discussion). Similar activities also lead to top soil loss associated with wind erosion, the second largest factor relating to soil degradation. While terrain deformation plays a lesser factor in degrading soils on a large scale, it is dominant in some of the more vegetated regions showing significant amounts of degradation. Soil compaction is frequently listed as a secondary cause of degradation. Overblowing of soil is a minor cause of degradation and is concentrated in a few very dry locations: Somalia, M adagascar, the southern shores of Lake Victoria, and some isolated parts of the Sahel and southern African regions.

The following is a hypothetical calculation of the soil water holding capacity reduction factor, RF. For a grid cell where the primary soil degradation classification is severe (degree) soil compaction (cause) rated as a frequent occurrence (extent), the soil degradation factor for the primary degradation cause $\left(\mathrm{RF}_{1}\right)$ is:

$$
\mathrm{RF}_{1}=1.00 \times \underline{1.00} \times 0.175=0.175
$$

and where the second soil degradation factor is moderate terrain deformation rated as a common occurrence

$$
\mathrm{RF}_{2}=\mathbf{0 . 7 5} \times \underline{0.50} \times 0.075=0.028
$$

The sum of $\mathrm{RF}_{1}$ and $\mathrm{RF}_{2}$ gives a total soil reduction factor (RF) of 0.203 or $20.3 \%$ for this location. To simulate the soil water holding capacity after degradation the original soil water holding capacity at the location is multiplied by (1.0 - RF).

Fig. $2 \mathrm{~b}$ shows the distribution of soil water holding capacity RF for the African continent. Clearly the areas most affected by soil degradation, and thus showing the most severe reductions in soil water holding capacities, are the dryland regions. Based on the GLASOD statis-

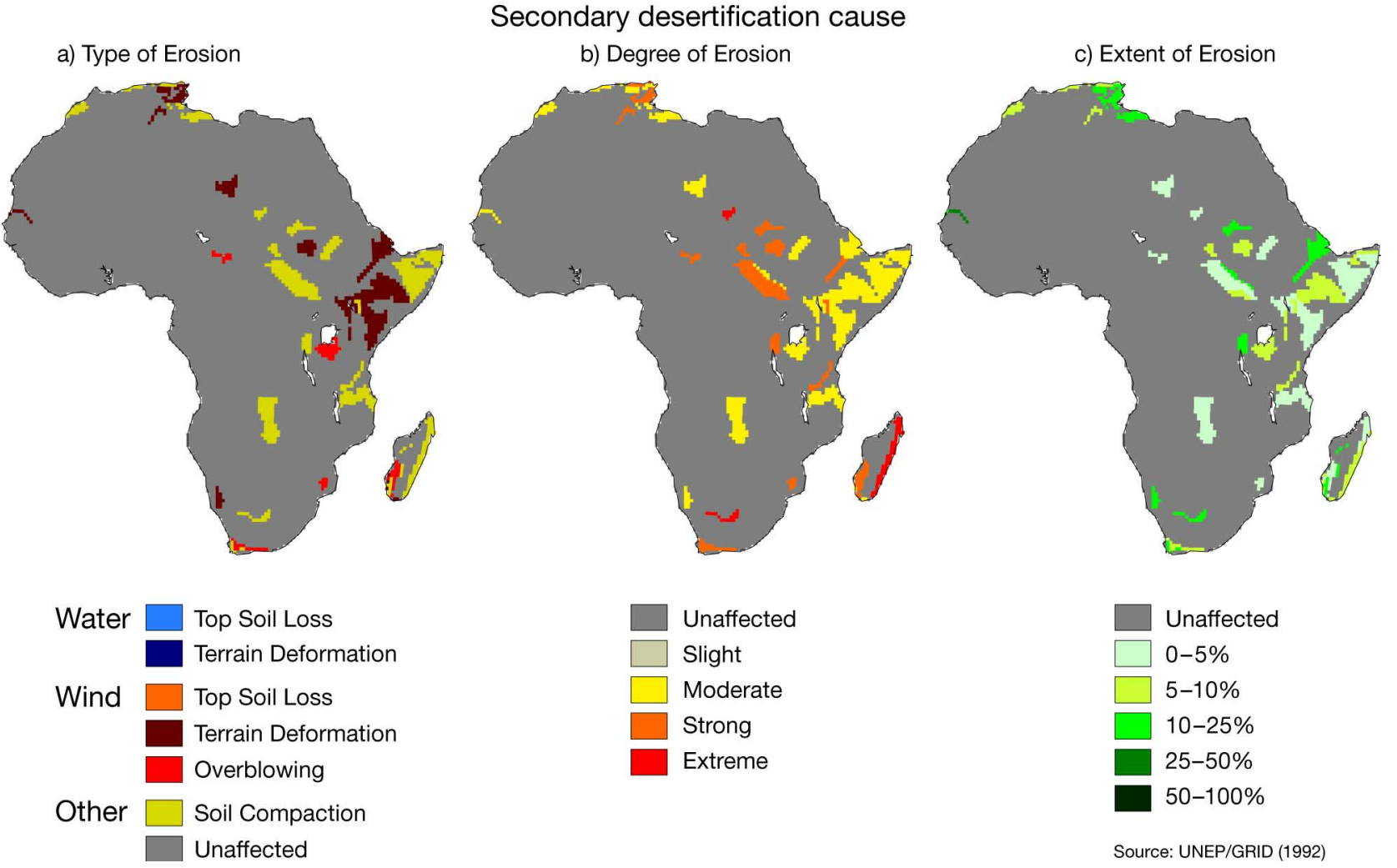

Fig. 4. Spatial distribution of (a) the secondary causes of soil degradation, (b) the degree of erosion from these causes, and (c) the spatial extent of erosion from these causes on the African continent. Source: GLASOD (OIdeman 1988) 
tics, the desert fringes are most susceptible to erosion. These include the Sahel region, and in South Africa the southern Kalahari and Great Karroo regions. Calculated RFs are on the order of $50 \%$ of the total water holding capacity of soils in these regions. It should be recognized that the qualitative nature of the GLASOD data make it difficult to make absolute comparisons between regions since experts may have different interpretations of the assigned categories related to cause, degree and extent of degradation. Other regions severely affected are the northern slopes of the Ethiopian Plateau, portions of Nigeria and Cameroon, Tunisia and Libya, and the highland areas of Madagascar. For a more detailed description of the processes and regions affected see Middleton \& Thomas (1992).

Experiment 1: validity of common soil water holding capacity assumptions. To test the impacts of using different soil water holding capacity $\left(w^{*}\right)$ assumptions, the water balance model was run at each $0.5^{\circ}$ by $0.5^{\circ}$ location on the African continent. In the first model run, each location was assigned a constant $150 \mathrm{~mm}$ soil water holding capacity. The second model run used the D\&W-derived soil water holding capacities. Climate inputs were identical for both model runs and are presented in Fig. 1. Consequences are assessed based on a comparison of model outputs from the 2 runs. Specific variables to be compared were annual total values of actual evapotranspiration $\left(E_{a}\right)$, moisture deficit (D) and moisture surplus (S) conditions at each grid location and averaged for the entire continent.
Experiment 2: impact of soil degradation on the African water balance. To test the impacts of soil degradation on the African water balance, a soil degradation scenario was created. The GLASOD soil moisture holding capacity reduction factors were applied to the $D \& W$ soil moisture holding capacities at each grid location. Using the same climate inputs as used in the first experiment, the model was run with the new soil moisture holding capacities. These results were then compared to results of the model run using the original D\&W soil moisture holding capacities. Water resource and climate impacts were evaluated in the same way as in the first experiment by comparing annual values of actual evapotranspiration $\left(E_{a}\right)$, moisture deficit (D) and moisture surplus (S) conditions at each grid location and averaged for the continent.

The first experiment was intended to show the importance of improving our estimates of soil water holding capacities for improving climate and hydrologic models. The second experiment was intended to assess the impact of desertification on local water resources.

\section{RESULTS}

\subsection{Experiment 1}

The first experiment compares the effect of using a constant $150 \mathrm{~mm}$ soil moisture holding capacity to the a) Control D\&W WHC

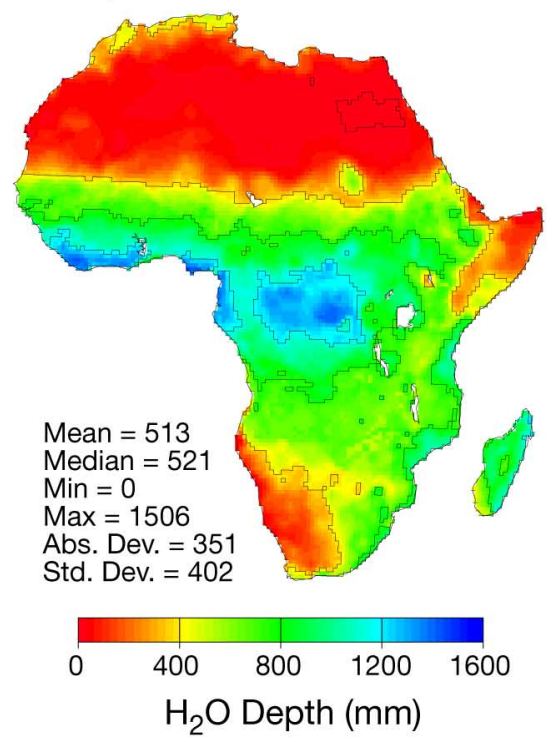

Actual evapotranspiration

b) Control 150 - Control D\&W

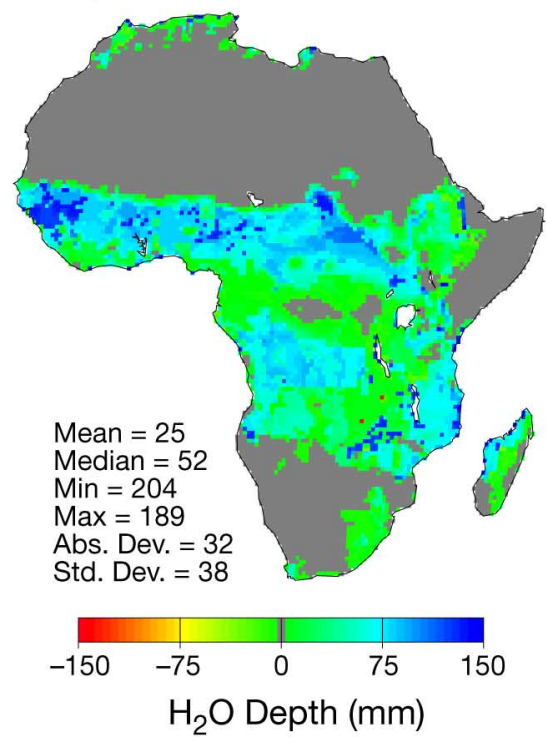

c) Degradation D\&W - Control D\&W

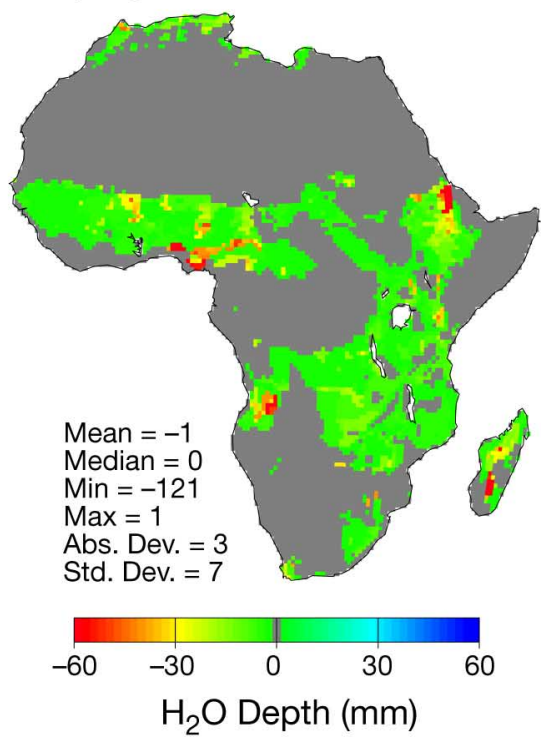

Fig. 5. Comparison of actual evapotranspiration estimates using: (a) the D\&W-derived soil water holding capacities; (b) difference map between the $150 \mathrm{~mm}$ model and the D\&W model; and (c) difference map between the desertification model and the D\&W model 
effect of using the D\&W-derived values for the continent. Fig. 5 presents the $E_{a}$ rates for the model run using D\&W soil water holding capacity values (Fig. 5a), and the differences between the constant $150 \mathrm{~mm}$ field capacity model and the D\&W model runs (Fig. 5b). The figure shows some very significant differences in the water distribution on the continent on the basis of the different soil moisture holding capacity assumptions. The regions most affected are those with seasonal wet and dry climates, particularly around the desert fringes, and to some extent locations with Mediterranean type climates (the north coast and cape regions). Also of note is that for large portions of the continent, particularly the desert areas with less than about $400 \mathrm{~mm} \mathrm{E}_{a}$, changing soil moisture holding capacities has no effect on $E_{a}$ rates. In these areas precipitation is inadequate to fill the local soil reservoirs. Therefore, under the assumptions of the model, all precipitation water is used for $E_{a}$ in both models. The only other unaffected areas are those where there is a year round surplus of rainfall in the Congo Basin.

Continent-wide $E_{a}$ is reduced by $25 \mathrm{~mm}$ on average, however this statistic is not really representative of the effective changes on the continent. In large portions of the Sahel, Angola, Republic of Congo, east Africa and Madagascar, estimates of $E_{a}$ are more than $75 \mathrm{~mm}$ lower, comprising between 20 and $25 \%$ of the total observed $E_{a}$. Some specific grid locations show extreme changes, in part because they were not originally classified in the $D \& W$ data. The very low $(5 \mathrm{~mm})$ soil water capacities assigned to these locations lead to large changes in the local water balance. In the case of 2 grid cells in Zambia, these changes reflect the fact that these grid points were classified as land in this study, but they are classified as water in the D\&W data set.

Because of the assumptions of the water balance model, the changes in moisture deficit and moisture surplus are of the same magnitude and locations as those observed for $E_{a}$ (Fig. 5b). However, it is worth evaluating the changes in the water balance from these perspectives. While the magnitude of deficit changes is greatest in the desert margins, perhaps the most dramatic changes from a moisture deficit point of view take place in those locations with relatively low moisture deficits initially. In these locations an additional $100 \mathrm{~mm}$ moisture deficit predicted by the $D \& W$ water holding capacity model means significant drought conditions during the dry season as compared to the $150 \mathrm{~mm}$ soil moisture holding capacity model, in which almost no drought is predicted during the dry season. While these changes in moisture deficit are smaller than those observed in the Sahel regions, they have a significant impact because they form a much larger proportion of the total observed deficit in these moister areas. Other areas strongly affected by changes in the soil moisture holding capacity assumption are southern east Africa and M adagascar. Changes in the moisture surplus conditions will occur during the wet season in the affected locations. Because of the generally lower soil water holding capacities in the D\&W scenario there is a significant increase in moisture surplus and runoff in locations that previously did not experience any moisture surplus. This is particularly evident in the expansion of the moisture surplus regions into the desert areas of the Sahel, east Africa and the Mediterranean coast.

\subsection{Experiment 2}

To evaluate the impact of soil degradation on A frican water resources, the D\&W scenario (control) was compared to a scenario where the D\&W soil water holding capacities were reduced by the soil moisture reduction factors calculated from the GLASOD data. Fig. 5a shows the estimated $E_{a}$ values for the $D \& W$ experiment, while Fig. $5 c$ shows the difference between the desertification and $D \& W$ scenario (note the change in scale for Fig. 5b compared to Fig. 5c). On a continental scale there is only a slight difference between the 2 scenarios, with a continent-wide difference in $\mathrm{E}_{\mathrm{a}}$ values of less than $2 \mathrm{~mm}$. However, there are several locations that show some dramatic differences between the scenarios. Difference values in excess of $50 \mathrm{~mm} \mathrm{yr}^{-1}$ are observed in Nigeria, Angola, northern Ethiopia, $M$ adagascar, and the Mediterranean coast. Other areas affected are Burkina Faso, portions of the east A frican highlands, and portions of Zambia.

To demonstrate the impacts of desertification on some of these regions, 7 water balance diagrams are presented in Fig. 6. In each diagram the $E_{a}$ lines for the $150 \mathrm{~mm}, \mathrm{D \& W}$ and desertification model runs are shown. Moisture deficit and moisture surplus conditions are shaded to indicate the different outcomes for each scenario. Each of these figures shows the increased moisture surplus conditions as field capacity is reduced at the respective locations (in all but Fig. 6a $150 \mathrm{~mm}<\mathrm{D \& W}<$ desertification; in Fig. 6a D\&W < $150 \mathrm{~mm}<$ desertification). Similarly, deficit conditions increase with decreasing soil water holding capacities. In the case of a double precipitation maximum location in east A frica (Fig. 6 d) surplus and deficit conditions are affected twice per year. In many of these areas changes in $\mathrm{E}_{\mathrm{a}}$ represent a $10 \%$ decrease in available soil moisture during the dry season (Fig. 5). Similarly, these are also the regions where moisture deficit conditions are not extreme but are significant (about 300 to $800 \mathrm{~mm}$ ) in the control run, and the changes in deficit represent a significant increase in the extent of drought conditions during the dry seasons. Therefore, these regions will 

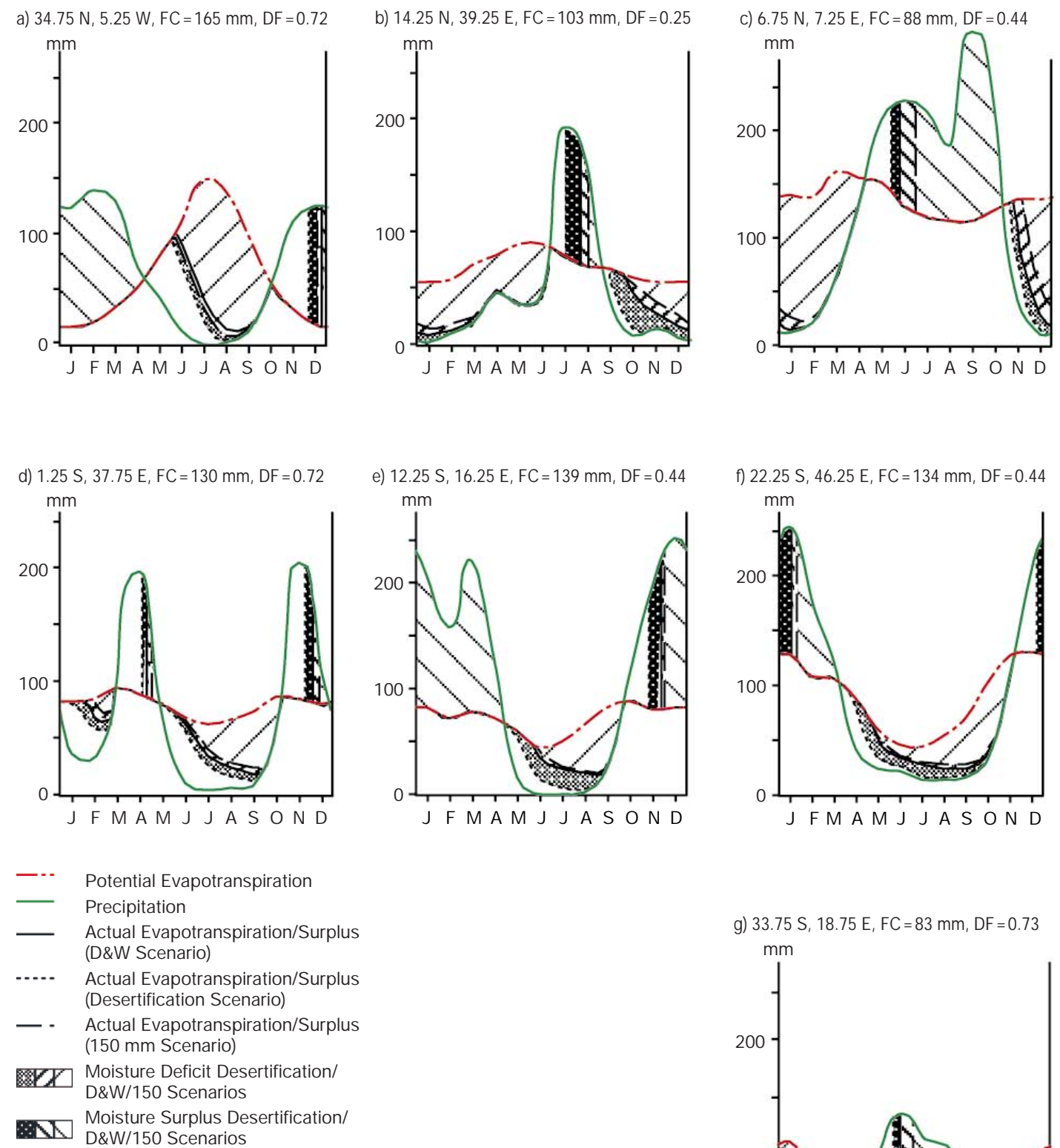

Fig. 6. Water balance diagrams at selected grid locations affected by soil degradation. Shaded areas show differences in moisture deficit and moisture surplus amounts based on water balance models using soil moisture holding capacities of $150 \mathrm{~mm}$, $D \& W$ estimates, and $D \& W$ estimates altered by the soil degradation data. FC: D\&W based $w^{*}$ value and DF $=1-$ RF

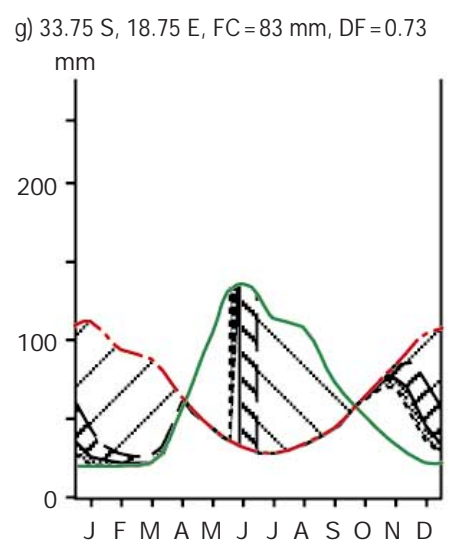

show a significant drying due to soil degradation. In terms of water surplus these changes are also significant in the local areas where moisture surpluses are typically relatively low. This could indicate a significant increase in local runoff during the rainy seasons.

\section{DISCUSSION}

Soil degradation as represented in this study almost always leads to a decrease in soil water holding capac- ities. On a continental scale, changes in $\mathrm{E}_{\mathrm{a}}$ rates are relatively small compared to observed values. However, significant changes in $\mathrm{E}_{\mathrm{a}}$ are observed in the seasonal wet and dry climates of the African continent. In general, as soil water holding capacity decreases there is an increased water deficit because less water can be held by the soil, particularly in regions experiencing long dry periods (e.g. Dunne \& Leopold 1978, $M$ ather 1978). Typically, reduced $E_{a}$ and increased moisture deficit conditions will occur over a few months following a wet period in seasonal wet and dry 
climates. Water surplus conditions are increased with decreased water holding capacity because of the decreased ability of soil to absorb excess rainfall. The net result is that moisture surplus will increase rapidly once the soil reservoir is filled during high precipitation periods. Therefore, as soil moisture holding capacity is decreased, surplus moisture will increase during periods of excess rainfall, $E_{a}$ will be reduced, and moisture deficit will increase during the dry periods following rainy conditions.

Results from this study show the importance of using accurate estimates of local soil moisture conditions. Using a constant $150 \mathrm{~mm}$ soil water holding capacity compared to the D\&W data shows that model estimates of $E_{a}$, moisture deficit, and moisture surplus conditions can be as much as $50 \%$ different between the 2 scenarios. As stated by Dunne \& Willmott (1996), the D\&W soil water holding capacities tend to be significantly lower than $150 \mathrm{~mm}$ for most locations. The result is that a constant $150 \mathrm{~mm}$ soil moisture holding capacity typically overestimates $E_{a}$ and severely underestimates moisture deficit and surplus conditions.

While on a continental scale the differences between the scenarios are relatively small, it is important to consider the changes in context of regions of human habitation. In almost all cases the Mediterranean and savanna climate regions are most affected; this coincides with the regions of highest population density. With the inherent assumptions of the model (i.e. there can be no moisture surplus until the soil reservoir is filled) only those areas that experience enough precipitation to fill the soil reservoir can experience moisture surplus conditions. This often implies a strong rainy season. Similarly, soil moisture deficits can only occur when precipitation is inadequate to meet $E_{p}$ and where these conditions persist long enough to dry out the soil. Therefore, decreasing soil water holding capacities along the desert margins increases soil moisture surplus and decreases $E_{a}$. Spatially, this results in the $D \& W$ scenario showing both moisture surplus and drought conditions extending further into the desert areas compared to the constant $150 \mathrm{~mm}$ scenario.

Similarly, but on a smaller scale and magnitude, the soil degradation model decreases soil water holding capacities for most locations, primarily in regions of high population densities. Interestingly, the largest changes in the water balance do not always coincide with regions of maximum soil degradation. This is particularly noticeable in southern Africa and along the northern Sahel. In both these locations, soil water holding capacities are predicted to decrease dramatically (on the order of $50 \%$ ), but this does not result in any change in the water balance variables. This discrepancy can be explained by the fact that in these locations the soil reservoir is never filled, and, therefore, no water is lost to the system during rain periods. This reflects a shortcoming of the model which only allows for moisture surplus conditions after the soil reservoir is filled. An improved model that distinguishes between direct overland flow and infiltration would better simulate runoff in these locations. However, this would require a significant increase in model input requirements, characterization of soil infiltration properties, and use of much smaller time and spatial scales in the model runs, making it impractical for this analysis. It is also interesting to note that while there are a few locations where soil water holding capacity is increased due to overblowing - only along the Somali coast where this is the primary soil degradation cause - this region is so dry as not to affect the moisture balance variables.

Areas most affected by soil degradation (Figs. 2 to 4 ) are agricultural areas rather than the regions where pastoralism is the dominant means of production. From a human food production perspective, it is precisely these areas that are most vulnerable to changes in the water balance, in part because of the lower flexibility these agricultural systems have in adapting to drought (e.g. Glantz 1987, 1992, Gleick 1992). Drought periods during the dry seasons are extended as soil moisture supplies dry up earlier, resulting in decreased $E_{a}$ values. This could have a dramatic impact on the length of the growing season, the types of crops that can be supported, and ultimately on local food and cash crop economies. In addition, a longer drought period can potentially increase erosion hazards, leading to a positive soil-climate feedback system. From a moisture surplus perspective, the increase in runoff translates into more extensive flooding conditions during wet seasons and the potential for significant increases in surface erosion by water agents. While clearly there are also impacts of soil degradation on the drier areas of the continent, it is these slightly wetter regions that suffer the worst consequences from a water resources perspective.

Geographically, the local climate regime can also exacerbate the impacts of soil degradation on local areas. In the tropical (especially east Africa) region where there is a double maximum of rainfall, the impact of soil degradation will be felt twice in the year, at the onset of each dry season, thus doubling the impact of reduced soil water availability compared to regions only experiencing 1 extended drought period. If we consider that the GLASOD data only represent soil degradation occurring between 1951 and 1980, and that soil degradation is showing little sign of slowing, then it becomes clear that in the future soil degradation will play an important role in altering local water balances, with the tropical double maximum rainfall regions being most vulnerable based on their local climate conditions. 
Several assumptions made by this study should be considered further. Only mean precipitation and temperature conditions are considered as climate inputs into the model, however it is well known that the dryland climates show extreme interannual variability (e.g. Hulme et al. 1992, Nicholson 1993). When considering the effects of climate variability, some of the regions that appear unaffected in this study will, in fact, suffer significant effects from soil degradation. For example, during a typical wet year soil reservoirs in these dry areas will be filled, and the consequences of soil degradation will be felt at this time. Furthermore, a region that has experienced severe soil degradation (such as that indicated along the northern Sahel or in South Africa) will find that vegetation recovery is severely reduced because there are less usable water supplies for vegetation. Because the soil reservoir in these regions is never filled when using the climatic average conditions, this study under-predicts the problems associated with these locations. With more realistic climate inputs and soil permeability assumptions, there will be periods when surplus water will increase in these locations, potentially increasing soil erosion further but also supplying more water for water storage facilities.

This study also assumes that there are no significant areas under irrigation, an assumption supported by Mabbutt (1989), although he does suggest that there are significant areas under irrigation in the Sudan region. If irrigation agriculture were to be practiced in the future in these degraded regions, the local water supply would be significantly affected by such practices. With irrigation, soil moisture storage will likely be greater during wet periods, resulting in an increased moisture surplus, ultimately reducing the usability of local water supplies (unless they are effectively captured and stored for later use in the dry season). In addition, the assumption that all water will be absorbed by the soil layer ignores the impact of soil degradation on local water balances in extremely dry regions. This makes the results of this experiment a conservative estimate of the impacts of soil degradation on the water balance. Finally, this study has not accounted for urbanization, which also would severely increase local runoff and reduce soil water holding capacities in a select few locations (e.g. Dunne \& Leopold 1978, Mather 1978).

\section{CONCLUSIONS}

Most environmental change models tend to simplify their soil water holding capacities by assuming a constant $150 \mathrm{~mm}$ soil water holding capacity for all locations. Results from this study show that this assumption can lead to significant errors when compared to a model using a derived variable soil water holding capacity database developed by Dunne \& Willmott (1996). Of particular importance is that the regions most affected by these assumptions are those that typically show the largest climate variability. On the African continent, it is the seasonal wet and dry climates (savanna and Mediterranean climates) that show the largest differences in actual evapotranspiration, moisture deficit and moisture surplus estimates. Since these are often the climates most studied to detect and model environmental change, it is important that accurate soil moisture estimates be calculated for these regions in particular.

Using the Dunne \& Willmott (1996) soil water holding capacity estimates as a control model and then comparing this to the estimated impacts of soil degradation from a model incorporating the GLASOD database (Oldeman 1988), this study shows that soil degradation occurring over a $30 \mathrm{yr}$ period (1950 to 1980) can have a severe impact on local water resources in seasonal wet and dry climate regions. Surprisingly, it may not be the driest regions that are most affected by these impacts, but rather it is the more productive agricultural areas in the wetter sub-humid climates that may have their water balance most affected by soil degradation. Changes include increased runoff during wet seasons and an extended drought period during the dry seasons. Given that these agricultural systems have less flexibility to respond to long-term desiccation as compared to pastoral systems, this could lead to significant changes in local growing seasons and perhaps overall productivity in the future. Although not presented in this study, if a constant $150 \mathrm{~mm}$ soil water holding capacity is used as the basis for the soil degradation study, the results will yield changes of the same sign and generally similar locations. However, the magnitude of these changes are significantly larger (almost double) than for the case presented here.

While this experimental project only looks at the effects of soil degradation from 1950 to 1980, the results suggest that future impacts of soil degradation can have significant impacts on local ecology and agricultural productivity. Many of the regions only slightly affected in the current study are likely to see some significant changes to their local water resources as soil water holding capacities are reduced by land degradation practices due to poor land management practices and population pressures. No studies suggest that these practices are slowing significantly at the present time.

Acknowledgements. This work was partly funded by the UCLA Academic Senate and NCAR. Thanks go to C. J. Willmott, K. A. Dunne and D. R. Legates for providing the clima- 
tology and soil data and UNEP/GRID program for providing the GLASOD data. I also thank Gerald Mills for his comments and suggestions.

\section{LITERATURE CITED}

Balling RC (1991) Impact of desertification on regional and global warming. Bull Am Meteorol Soc 72:232-234

Bryant NA, J ohnson LF, Brazel AJ, Balling RC, Hutchinson CF, Beck LR (1990) M easuring the effect of overgrazing in the Sonoran desert. Clim Change 17:243-264

Charney J G (1975) Dynamics of deserts and drought in the Sahel. Q J R M eteorol Soc 101:193-202

Conway D, Krol M, Alcamo J, Hulme M (1996) Future availability of water in Egypt: the interaction of global, regional and basin scale driving forces in the Nile basin. Ambio 25(5):336-342

Dregne HE (1983) Desertification of arid lands. Harwood, New York

Dunne K, Willmott CJ (1996) Global distribution of plantextractable water capacity of soil. Int J Climatol 16: 841-859

Dunne T, Leopold LB (1978) Water in environmental planning. WH Freeman and Co, New York

El-Baz F, Hassan MHA (1986) Physics of desertification. Martinus Nijhoff, Dordrecht

Feddema JJ (1998) Global warming: can tropical Africa be neglected? Environment and Development Monograph Series, Indiana Center on Global Change and World Peace, Indiana University, Bloomington

Feddema J J , M ather J R (1992) Hydrological impacts of global warming over the United States. In: Majumdar SK, Kalkstein LS, Yarnal BM, Miller EW, Rosenfeld LM (eds) Global climate change: implications, challenges and mitigation measures. The Pennsylvania Academy of Sciences, Easton, p 50-62

Federer CA, Vörösmarty C, Fekete B (1996) Intercomparison of methods for calculating potential evapotranspiration in regional and global water balance models. Water Resour Res 32(7):2315-2321

Franchito SH, Rao VB (1992) Climatic change due to land surface alterations. Clim Change 22:1-34

Glantz M H (ed) (1987) Drought and hunger in Africa: denying famine a future. Cambridge University Press, Cambridge

Glantz MH (1992) Global warming and environmental change in sub-Saharan Africa. Global Environ Change, September: 183-204

Gleick PH (1992) Climate change and international politics: problems facing developing countries. Ambio 18(6): 333-339

Houghton J T, Callender BA, Varney SK (eds) (1992) Climate change 1992: the supplementary report to the IPCC scientific assessment. Cambridge University Press, Cambridge

Houghton J T, J enkins GJ , Ephraums J J (eds) (1990) Climate change: The IPCC scientific assessment. Cambridge University Press, Cambridge

Hulme M (1994) Is environmental degradation causing drought in the Sahel? An assessment from recent empirical research. Geography 74:38-46

Hulme M (1996) Recent climatic change in the world's drylands. Geophys Res Lett 23(1):61-64

Hulme M, Conway D, J oyce A, Mulenga H (1996) A 1961-90 climatology for Africa south of the equator and a comparison of potential evapotranspiration estimates. S Afr J Sci 92:334-343

Hulme M, Kelly M (1993) Exploring the links between deser- tification and climate change. Environment 35(6):4

Hulme M, Marsh R, J ones PD (1992) Global changes in a humidity index between 1931-60 and 1961-90. Clim Res 2(1):1-22

J ackson RD, Idso SB (1975) Surface albedo and desertification. Science 189:1012-1013

Kemp R (1991) Global environmental issues: a climatological approach. Routledge, London

Lare AR, Nicholson SE (1990) A climatonomic description of the surface energy balance in the central Sahel. Part I: Shortwave radiation. J Appl Meteorol 29(2):123-137

Legates DR, Willmott CJ (1990a) Mean seasonal and spatial variability in gauge-corrected global precipitation. Int J Climatol 10:111-127

Legates DR, Willmott CJ (1990b) Mean seasonal and spatial variability in global surface air temperature. Theor Appl Climatol 41:11-21

Mabbutt J A (1989) Impacts of carbon dioxide warming on climate and man in the semi-arid tropics. Clim Change 15: 191-221

Manabe S, Wetherald RT (1987) Large-scale changes in soil wetness induced by an increase in carbon dioxide. J Atmos Sci 44:1211-1235

M ather J R (1978) The climatic water budget in environmental analysis. Lexington Books, Lexington

Mather J R, Ambroziak RA (1986) A search for understanding potential evapotranspiration. The Geogr Rev 76(4):355-370

Middleton NJ , Thomas DSG (1992) World atlas of desertification. United Nations Environment Programme, Geneva

Mintz Y, Serafini YV (1992) A global monthly climatology of soil moisture and water balance. Clim Dyn 8:13-28

Mintz Y, Walker GK (1993) Global fields of soil moisture and land surface evapotranspiration derived from observed precipitation and surface air temperature. J Appl M eteorol 32(8):1305-1334

Nicholson SE (1989) Land surface atmosphere interaction: physical processes and surface changes and their impact. Prog Phys Geogr 12:36-65

Nicholson SE (1993) An overview of African rainfall fluctuations in the last decade. J Clim 6(7):1463-1466

Nicholson SE, Lare AR (1990) A climatonomic description of the surface energy balance in the central Sahel. Part II: The evapoclimatonomy submodel. J Appl Meteorol 29(2): 138-146

Oldeman LR (ed) (1988) Guidelines for general assessment of the status of human-induced soil degradation. Working paper and preprint 88/4. ISRIC, Wageningen

Oldeman LR, Hakkeling RTA, Sombroek WG (1990) World map of the status of human-induced soil degradation. An explanatory note. ISRIC/UNEP, Wageningen

Schlesinger WH, Reynolds J F, Cunningham GL, Huenneke LF, Jarrel WM, Virginia RA, Whitford WG (1990) Biological feedbacks in global desertification. Science 147: 1043-1048

Shukla J , Mintz Y (1982) Influence of land-surface evapotranspiration on the earth's climate. Science 215:1498-1501

Sud YC, Chao WC, Walker GK (1993) Dependence of rainfall on vegetation: theoretical considerations, simulation experiments, observations, and inferences from simulated atmospheric soundings. J Arid Environ 25:5-18

Syers J K, Lingard J, Pieri C, Ezcurra X, Faure G (1996) Sustainable land management for the semiarid and subhumid tropics. Ambio 25(8):484-491

Thomas DSG, M iddleton NJ (1994) Desertification: exploding the myth. J ohn Wiley \& Sons, Chichester

Thornthwaite CW (1948) An approach toward a rational classification of climate. Geogr Rev 38(1):55-94 
Thornthwaite CW, M ather J R (1955) The water balance. Publ Climatol 8(1):1-104

Vörösmarty CJ, Moore B III, Grace AL, Gildea MP, Melillo J M, Peterson BJ , Rastetter EB, Steudler PA (1993) Continental scale models of water balance and fluvial transport: an application to South America. Global Biogeochem Cycles 3(3):241-265

Walker J , Rowntree PR (1977) The effect of soil moisture on circulation and rainfall in a tropical model. Q J R M eteorol Soc 103:29-46

Warren A, Sud YC, Rozanov B (1996) The future of deserts. J Arid Environ 32:75-89

Williams MAJ, Balling RC (1996) Interactions of desertification and climate. For WM O/UNEP. Arnold Press, London Willmott CJ (1977) WATBUG: a FORTRAN IV algorithm for

Editorial responsibility: Laurence Kalkstein, Newark, Delaware, USA calculating the climatic water budget. Publ Climatol 50(1) Willmott CJ , Rowe CM , M intz Y (1985) Climatology of the terrestrial seasonal water cycle. J Climatol 5:589-606

Wilm HG, Thornthwaite CW, Colman EA, Cummings NW, Croft AR, Gisborne HT, Harding ST, Hendrickson AH, Hoover MD, Houk IE, Kittredge J, Lee CH, Rossby CG, Saville T, Taylor CA (1944) Report of the Committee on Evaporation and Transpiration, 1943-44. Trans Am Geophys Union 25(5):683-693

Xue Y, Shukla J (1993) The influence of land surface properties on Sahel climate. Part I: Desertification. J Clim 6(12): 2232-2245

Zheng X, Eltahir EAB (1997) The response to deforestation and desertification in a model of West African monsoons. Geophys Res Lett 24(2):155-158

Submitted: J une 3, 1997; Accepted: March 4, 1998

Proofs received from author(s): J une 25, 1998 